Revista Iberoamericana, Vol. LXXVII, Núm. 234, Enero-Marzo 2011, 177-193

\title{
LOS CÓMICS EN UN PAÍS TROPICAL: PALOMAR DE GILBERT HERNÁNDEZ
}

\author{
POR \\ Juan Poblete \\ University of California, Santa Cruz
}

En los años treinta del siglo pasado y como parte del esfuerzo del período de entreguerras por neutralizar el nazismo en expansión, el gobierno de Franklin Delano Roosevelt creóla Oficina del Coordinador de Asuntos Interamericanos dentro de la sección películas del Departamento de Estado norteamericano. Su propósito declarado, dice el crítico José Piedra, fue "mostrar la verdad acerca del 'estilo de vida estadounidense' y para ese efecto se contrató a los estudios de Hollywood para que crearan propaganda destinada a desarrollar las promesas de la Política del Buen Vecino (el nombre que Roosevelt le dio a su política interamericana)" (Piedra 148). Uno de estos estudios hollywoodenses fue el de Disney. Julianne Burton añade la siguiente aparente paradoja: "mientras que el proyecto de Disney para Sudamérica fue construido sobre la base de una conciencia crítica de muy altos niveles del gobierno estadounidense para representar lo latino con el deseo de representar su cultura y experiencias con autenticidad y respeto en cuanto a las diferencias intra e interregionales” (133-34; traducción mía) en una serie de documentales educativos y tres películas, que incluyen South of the Border with Disney (1941), Saludos Amigos (1943) y The Three Caballeros (1945), dicho esfuerzo terminó representando, a través de un trabajo semiótico-industrial, un completo reempaquetamiento ideológico metropolitano de aquellos materiales primarios. En The Three Caballeros, este esfuerzo alcanzó, a través de un caso peculiar del retorno de lo reprimido, el estatus de una completa "alegoría del colonialismo del primer mundo". Burton concluye: "El regalo de entendimiento intercultural de Disney terminó siendo el acto de reempaquetar a América Latina para un más efectivo consumo norteamericano" (Burton 133-46; traducción mía).

En este contexto, es pertinente preguntarse cómo es posible que a pesar de la explícita misión de Disney de producir una representación más realista y positiva de la cultura latinoamericana en toda su especificidad, estos filmes terminaran reproduciendo muchos de los estereotipos del imaginario colonial. Preguntarse en otras palabras ¿qué tipo de inconciente político-cultural se manifiesta aquí envolviendo y limitando estas producciones de Disney? 
La pregunta sirve para enmarcar este ensayo sobre la obra Palomar del artista latino Gilbert Hernández. Mi hipótesis es que la obra de este autor se organiza a partir de un esfuerzo muy consciente por resistir y transformar la maquinaria norteamericana para la representación del otro étnico y por reinventar una nueva máquina semiótica que produzca una representación más satisfactoria para todos los públicos involucrados. Y que esto es tanto el resultado de una conciencia político-étnica cuanto el producto de una sensibilidad artística contestataria más amplia conectada a la música punk y a los cómics alternativos. Al hacerlo, Hernández invierte de hecho, al menos significativa sino totalmente, el proceso de producción de lo latino y la latinidad en la cultura estadounidense dominante. Si en ella lo latino es presentado en el mercado general como una población y una cultura extranjeras y en el mercado literario como una población representada en inglés por una cierta maquinaria textual para beneficio de un público anglo y monolingüe en inglés, en Palomar, en cambio, la maquinaria de la representación inventa sus propios procedimientos a partir de un sustrato bicultural. En este sentido, Palomar y la serie más amplia de Love and Rockets son un esfuerzo sostenido de contra-tropicalización.

\section{LA REPRESENTACIÓN DEL OtRo LATIN/O/AMERICANO EN LOS EsTADOS UNIDOS}

En su libro Latinos Inc. The Marketing and Making of a People, Arlene Dávila ha estudiado el proceso a través del cual los individuos son transformados en consumidores y las poblaciones en mercados. Si a nivel de la política la participación se traduce en poder, entonces los latinos en los Estados Unidos continúan siendo las víctimas de su invisibilidad. Su participación demográfica no tiene correlato o equivalencia real en el ámbito del poder político. Si, por otro lado, se considera al mercado como un espacio social en que la participación se traduce en consumo y en reconocimiento público por parte de las empresas comerciales, entonces los latinos han alcanzado grandes cuotas de visibilidad. La tesis de Dávila es que esta relación de visibilidad/invisibilidad se da en detrimento de la verdadera complejidad de las poblaciones latinas en los Estados Unidos y significa un límite a sus formas posibles de participación política. De este modo, los latinos son definidos fundamentalmente desde una perspectiva cultural y no política. Así, son presentados en sus influyentes identidades (representaciones) mediáticas como un pueblo culturalmente homogéneo definido por una lengua única (el español), una serie de valores tradicionales respecto a la familia y una religión (la católica). La "verdad" de los latinos es producida por una serie de discursos especializados desarrollados por múltiples agentes que constituyen una identidad mediada o negociada. Central a esta producción de conocimiento es la labor que desarrollan las empresas de marketing y publicidad. Su estrategia consiste en reclamar la figura de la autenticidad y del saber étnico frente a las necesidades que las grandes compañías norteamericanas tienen de alcanzar a ese sector de sus audiencias o públicos posibles. Una serie de estereotipos

\footnotetext{
Revista Iberoamericana, Vol. LXXVII, Núm. 234, Enero-Marzo 2011, $177-193$
ISSN 2154-4794 (Electrónico)
} 
racistas y reductores son movilizados para producir una serie de "valores" latinos, un "look" latino y una imagen de lo hispano definida por su permanente falta de aculturación en el ámbito de la sociedad y la cultura estadounidense y su supuesta necesidad de constante retroalimentación respecto a América Latina (Dávila).

En el contexto general del análisis de la literatura latina en los Estados Unidos he propuesto en otro lugar (Poblete) dos hipótesis de trabajo para explorar el campo. Mi primera hipótesis era que la mejor literatura latina obliga potencialmente a la literatura nacional estadounidense (pero también a la literatura latinoamericana) a enfrentar, en tiempos de globalización cultural y de la cultura de la globalización, su carácter de formación literaria heterogénea y, por lo tanto, a aceptar la inevitabilidad de la traducción cultural y lingüística como uno de sus elementos constitutivos. Esta heterogeneidad constitutiva ingresa en la literatura nacional estadounidense en tanto ésta se esfuerza por asimilar, por la vía de su incorporación a la tradición literaria nacional, a una literatura como la latina que, escrita en al menos dos lenguas y desde dos imaginarios culturales, resiste activamente los términos de tal asimilación.

Mi segunda hipótesis sostenía que la mejor literatura latina se esfuerza por transformar la lectura multicultural monolingüe, y en rigor monocultural norteamericana o nacional, en un verdadero encuentro intercultural en donde los resultados no hayan sido limitados a la traducción o asimilación uniformante de la diferencia o a su exotización puramente comercial, sino que permanezcan abiertos al cambio y a la verdadera experiencia de y en la otredad en un contexto globalizado. Contrariamente a cierta literatura latina aún dominante en los Estados Unidos, sus mejores exponentes quieren problematizar activamente todo esfuerzo por reducir la complejidad de la experiencia latina a los clichés de una economía textual especializada en la domesticación de la alteridad étnica.

A este proceso de producción social de la imagen de lo latino debe añadirse el igualmente poderoso aparato estadounidense para la representación de lo latinoamericano. En su excelente libro, The United States and Latin America: Myths and Stereotypes of Civilization and Nature, el historiador norteamericano Frederick B. Pike sostiene que estos mitos y estereotipos tienen una raíz colonial inglesa y responden a una clasificación binaria del mundo que lo divide entre los civilizados y los bárbaros. Con este sustrato, las visiones estadounidenses de lo latinoamericano han tenido siempre el doble propósito de justificar el imperialismo y expansionismo norteamericano y de confirmar al yo estadounidense en su posición de autoconcedido privilegio. Aunque, como muestra el libro, esta es una historia que tiene sus desarrollos específicos a lo largo del tiempo, Pike cree encontrar la matriz generadora de sus variadas manifestaciones en la oposición entre lo norteamericano y lo latinoamericano a partir de su relación supuesta con la naturaleza. Mientras los norteamericanos se autocaracterizan como un pueblo fundamentalmente orientado hacia el futuro y el progreso, medidos bajo los supuestos de acumulación material y dominio y explotación eficiente de la naturaleza de acuerdo a una racionalidad instrumental que se autodescribe en términos de superación

Revista Iberoamericana, Vol. LXXVII, Núm. 234, Enero-Marzo 2011, $177-193$
ISSN 2154-4794 (Electrónico) 
moral y autocontrol; los latinoamericanos son percibidos como la imagen invertida en el espejo. A ellos los define su relación dependiente con esa naturaleza, de la cual son más víctimas que señores. Esta falta de control sobre lo natural se manifiesta tanto en su sentido interno como externo, tanto en la falta de desarrollos materiales como en la dudosa moralidad. En este sentido, ya sea para explotarlos o para civilizarlos, los latinoamericanos son vistos como niños irresponsables e impulsivos más cercanos al estado de naturaleza que a la cultura civilizada.

La última vuelta de tuerca en el libro de Pike se refiere a dos procesos que complican la estructura binaria, aunque siguen dependiendo de ella. Estos procesos son los que Pike llama "Americanización de América Latina” y de "Latinoamericanización de los Estados Unidos". En su descripción, el autor oscila entre la tesis de los estereotipos de representación ahora modificados y la afirmación de procesos históricos de cambio real en ambas sociedades. El primer proceso alude tanto al impacto de los medios de comunicación masiva como a la importancia de los centros comerciales y del consumismo en la vida diaria de los latinoamericanos. El segundo proceso concierne tanto a la llegada de millones de inmigrantes latinoamericanos recientes como a la presencia de narcotraficantes y pandillas (ambas formas de ‘invasión’ latinoamericana son violentas en este imaginario). Latinoamericanización alude asimismo a la imposición de una estructura tributaria y un modelo económico neoliberal que favorece groseramente a los ricos y perjudica a la clase media y a los pobres como también a la pérdida del liderazgo productivo industrial a manos de Japón y Alemania y al relajamiento en las costumbres (Pike, capítulo X).

En Tropicalizations: Transcultural Representations of Latinidad, Frances Aparicio y Susana Chávez-Silverman proponen dos conceptos útiles para pasar al análisis de Palomar. Definiendo "tropicalizaciones" señalan:

A diferencia de la unidireccionalidad implícita en la teoría de [Edward] Said sobre el orientalismo en la cual el mundo árabe es representado por la mirada europea dominante, construido exclusivamente por discursos europeos (y por lo tanto privado de "agencia” respecto a su propia historia e identidad cultural colectiva), el marco conceptual de las tropicalizaciones [...] nos permite incluir, como señala Silvia Spitta acerca de la transculturación, "las dinámicas de la colonia desde el punto de vista de los colonizados”. (Aparicio y Chávez-Silverman 2; traducción mía)

Estas tropicalizaciones implican "el uso de tropos, la asignación a un espacio, geografía, grupo o nación de un conjunto de características, imágenes y valores”. En lo que concierne a América Latina, las tropicalizaciones hegemónicas, dicen Aparicio y Chávez-Silverman, reproducen y producen una "idea mítica de latinidad basada en proyecciones anglo (o dominantes) del miedo” (Aparicio y Chávez-Silverman 8).

\footnotetext{
Revista Iberoamericana, Vol. LXXVII, Núm. 234, Enero-Marzo 2011, $177-193$
ISSN 0034-9631 (Impreso)
} 
El segundo concepto útil para efectos de este ensayo es el grupo de variantes que las autoras identifican en su esfuerzo por introducir un dinamismo multilateral y evitar el binarismo estático propio del modelo orientalista. En concreto, se refieren a tres variantes importantes. Primero, la idea de "tropicalizar desde" (Aparicio y Chávez-Silverman 11) adentro o afuera del objeto de estudio; en segundo lugar, la idea de "autotropicalización estratégica” en donde la resistencia se junta con la resemantización de los códigos dominantes (Aparicio y Chávez-Silverman 12; Aparicio 199) y, finalmente, el peligro lógico de esta última: la "autotropicalización acrítica" o fallida en donde el esfuerzo de reapropriación fracasa en una recepción que confirma los prejuicios culturales del lector o espectador y agrava o promueve los estereotipos que afectan la representación de los latinos y latinoamericanos en los Estados Unidos. Con esta batería de conceptos es posible ahora pasar a analizar algunos aspectos salientes de Palomar.

PALOMAR Y LAS TROPICALIZACIONES DOMINANTES Y CONTRAHEGEMÓNICAS

La extensa serie de cómics que constituyen el libro Palomar fue publicada a lo largo de un período que cubre originalmente desde 1981 hasta 1996 y que se reinicia en 2001 y continúa hasta la fecha. En 1981, los hermanos Jaime, Mario y Gilbert Hernández autopublicaron el primer número de la serie Love and Rockets (así llamada por su mezcla originalmente de historias de amor y ciencia ficción) en formato de revista o fanzine. Muy pronto Gary Groth, fundador de la editorial Fantagraphics les ofreció un contrato y de este modo, las dos sagas que los Hernández produjeron se transformaron en los cómics fundamentales de la casa editorial y ayudaron a definir el fenómeno del cómic alternativo en los años ochenta y noventa en los Estados Unidos. Las historias de Jaime Hernández sobre un vecindario imaginario de Los Angeles llamado Hoppers incluyen el paso de dos "locas” lesbianas punk, Margarita Luisa "Maggie” Chascarrillo y Esperanza Leticia "Hopey” Glass, de la adolescencia a la adultez. Las historias de Gilbert se ambientaban por su parte en un pueblo centroamericano imaginario llamado Palomar, en donde una extraordinaria serie de mujeres da vida a una saga memorable. Al nivel más general, puede decirse que la serie de Love and Rockets hizo historia de varias maneras: fue, por ejemplo, el primer cómic norteamericano que adaptó con éxito la fórmula europea de recoger en formato de libro cómics que habían sido publicados previamente en formato de revista (Groth et al 61). De hecho, en 2003 para Palomar y en 2004 para Locas, Fantagraphics lanzó al mercado las dos series completas agrupando en un volumen, en cada caso, los varios libros de cómics que las historias de las más de cincuenta revistas Love and Rockets habían producido. ${ }^{1}$ Las dos series son famosas,

1 Ésta es la edición de Palomar que uso para este trabajo. Todas las referencias de página corresponden, pues, a esta edición.

ISt) 
además, por presentar personajes psicológicamente complejos en la forma de mujeres fuertes que no son super-héroes en el sentido de los cómics dominantes, sino personas de carne y hueso que viven, aman, sufren y envejecen como el resto de nosotros.

La historia de Palomar empieza llamándose "Sopa de gran pena” (así en español y traducido luego a "Heartbreak Soup”, que será el subtítulo de todas las historias en la serie de Palomar) y contiene al pie de página una traducción fonética de la frase: “Sopa de gran pena (soap-uh deh grawn pen-uh): heartbreak soup" (14).

La nota nos pone sobreaviso de uno de los grandes aciertos de Gilbert Hernández. Aunque escrita casi completamente en inglés, la saga de Palomar está siendo relatada -al menos en la verdad que el relato quiere construir para sí mismo- en español, o más bien en "glorious español unless otherwise noted", como repite con frecuencia (479). Esta lengua gloriosa es, más allá de las apariencias, un idioma conceptual que manifiesta tanto el deseo de hablar español -cuya posibilidad les fue negada a Hernández y sus hermanos en la ciudad donde se criaron, Oxnard, California, debido a las presiones de la cultura estadounidense para la rápida asimilación de la misma por parte de los inmigrantes y sus hijos- cuanto el punto de vista subjetivo y étnico que anima el discurso del narrador latino de estos cómics. La traducción en la nota al pie de página señala que entre el discurso del original y el mundo que representa, y el lector más probable de esta historia (el público monolingüe en inglés norteamericano) hay simultáneamente una relación de cercanía y de distancia, de familiaridad y distanciamiento que conviene no olvidar. A esto le he llamado heterogeneidad en el contexto de la literatura latina (Poblete). De hecho, cuando el inglés aparece en la historia, ya sea porque un turista norteamericano visita el pueblo o porque algunos de sus habitantes, y así parte de la acción, se desplacen a los Estados Unidos, lo hará «entre comillas», para marcar su diferencia con el lenguaje y la perspectiva profundas en "glorioso español" que presiden la narración. Es decir, el lector debe percibir que aun cuando aquella ocurra epifenómicamente en inglés, lo que lee es un código y un mundo que no debe asimilar demasiado rápidamente a sus patrones interpretativos habituales.

En el origen y desarrollo del pueblo Palomar hay seis personajes que representan aspectos claves de dicha historia. Ellos son Chelo, Luba, Carmen, Tonantzin, Heraclio y Miller. Chelo, Luba y Carmen forman parte de la galería de mujeres fuertes que le dan su carácter matriarcal a esta comunidad en tanto la fundan y gobiernan, además de brindarle grandes dosis de sentido común y valentía, y ayudar a dar a luz, limpiar, regular y dirigir a los hombres y sus impulsos. Tonantzin, Heraclio y Miller nos hablan de la relación entre la política, los intelectuales y las formas de la representación política y estética.

De este modo, muy al comienzo de la historia de Palomar, apenas en la segunda entrega, se proponen varios inicios tentativos para la saga: tal vez empieza, se dice, con tres historias de amor (fallidos y exitosos), o tal vez con la llegada desde el norte de Luba al pueblo, o quizás con la muerte de Toco, o la ida a los Estados Unidos de Soledad

\footnotetext{
\begin{tabular}{l} 
Revista Iberoamericana, Vol. LXXVII, Núm. 234, Enero-Marzo 2011, $177-193$ \\
\hline ISSN 0034-9631 (Impreso)
\end{tabular}
} 
Márquez, que hace posible que se consume sexualmente uno de aquellos amores, o tal vez, finalmente, cuando sin saber que ya estaba muerto, Heraclio vio por primera vez al fantasma de Pintor (36-37).

Luba, quien llegó del norte a Palomar y es llamada la india (pues su padre lo era), se instala primero como una bañadora de hombres y construye poco a poco su red de negocios en el pueblo. Ésta incluye los baños, el único cine del pueblo y, finalmente, el cargo de alcaldesa de Palomar. Con su llegada, Luba desplaza del negocio a Chelo (que era hasta entonces la única bañadora del pueblo) y ésta pasa a ser la sheriff de Palomar. Desde estas posiciones, las dos mujeres controlarán buena parte de la acción en Palomar y, en el caso de Luba, generarán, literalmente, a muchos de los personajes que comenzarán a popular sus calles y a producir sus historias. Más que intentar describir las siempre proliferantes identidades de las varias docenas de personajes que, a partir de Luba y Chelo entre otras, le dan su textura a Palomar, interesa aquí destacar que estas dos matronas fundan un mundo organizado y dirigido por mujeres, en donde los hombres son, con mucha frecuencia, vistos con ironía. En las palabras de Carmen, Palomar es un pueblo "Donde los hombres son hombres y las mujeres necesitan el sentido del humor” (17). ${ }^{2}$

A partir de esta descripción, sería fácil imaginar a Luba como una matriarca tradicional, una suerte de abuela de todos, venerada como el origen de la comunidad. Nada estaría más lejos de la verdad. Si bien es cierto que Luba da a luz a por lo menos seis hijas, cada una de ellas tendrá un padre diferente y a menudo desconocido; y aunque es cierto que Luba está dotada de unos senos prominentes que funcionan como un imán para muchos hombres, también lo es que sus piernas flaquísimas no tienen ninguna proporción con su torso y que con frecuencia se la ve empuñando un martillo que le ayuda a lidiar, violentamente, con varios de los hombres que se cruzan en su paso. Aún más, con la misma constancia, el lector ve a Luba tratando de seducir primero y luego teniendo relaciones sexuales con un varón menor de edad que ha alcanzado la pubertad. Desde este punto de vista, interesa destacar cómo en Luba, y en Palomar en general, el principio generador, tanto en lo narrativo como en lo visual, no es exactamente la completa eliminación de los estereotipos, sino más bien su mezcla algo anárquica con

\footnotetext{
2 En Luba y en Chelo, o más específicamente en la representación de sus físicos, se juntan asimismo dos de las tradiciones o estilos visuales que dan vida a Palomar: son a menudo mujeres que parecen salidas de un cómic de la cultura dominante (con senos o músculos hiperdesarrollados) y son a la vez mujeres que engordan y tarde o temprano envejecen. A lo largo del texto, algunas mujeres y los indígenas son con frecuencia respresentados como si pertenecieran al mundo de los cómics dominantes de aventuras, ciencia ficción o super-héroes. Véase al respecto el ensueño de Jesús, que en prisión y en la misma página, imagina a Luba, a Tonantzin y a su mujer, con tres estilos diferentes de representación de la mujer en el comic: la amazona de aventuras, la chica voluptuosa del cómic de los años cincuenta y la mujer y madre trabajadora de la tradición realista. Sobre la complejidad del retrato de las mujeres en los dos hermanos Hernández, véanse Benfer y Merino.
}

ISSN 0034-9631 (Impreso) 
lo inesperado y lo irreverente. El verosímil de Palomar se define así por el modo de apropiación y combinación original de las diferentes maquinarias de representación que los varios discursos en que abreva la imaginación de Hernández le proporcionan.

Las grandes empresas tradicionales, como Marvel y DC Comics, han controlado durante años el mercado de los cómics por la vía tanto de sus múltiples super-héroes (Superman, Batman, Wonder Woman, Captain America, Iron Man, Spider Man, etc.) de abundantes músculos y poderes extraordinarios, como de sus curvilíneas mujeres en trajes apretados, ofreciendo así una combinación en extremo atractiva para sus públicos de adolescentes masculinos. Gilbert Hernández aprendió de ellos, a partir del ejemplo de su madre, a quien a la vez su madre le había prohibido esas revistas (Groth et al 63); pero muy pronto intuyó que le sería imposible competir con esos dibujantes profesionales en su propio terreno. ${ }^{3}$ El rescate vino de la mano del punk y la cultura contracultural.

Los hermanos Hernández han citado con frecuencia sus múltiples influencias en el terreno de los cómics, además de los super-héroes del comienzo infantil ejemplificados por la obra de Jack Kirby, aparecen en este panteón Charles Schultz (de Peanuts), Robert Crumb (Zap Comix), y muchos más (Royal 239). Junto a ellos, Gilbert ha mencionado también el fuerte impacto del cine: "Diría que cuando estoy dibujando las influencias directas serían primero los artistas de cómics y luego los cineastas. Ambos se complementan” (Royal 237). ${ }^{4}$

Y más explícitamente:

\begin{abstract}
"Heartbreak Soup” estuvo conmigo desde mis años adolescentes. Ese fue mi período de fanático ["geek”] del cine, cuando comencé a ver toda película hecha antes de 1950 que dieran en la tele. [...] Luego progresé hacia las películas de los cincuentas y me metí en las películas extranjeras y cuando miraba películas de Sofia Loren como Ayer, hoy y mañana o cuando vi Orfeo Negro siempre pensé: “esto sería perfecto para una gran serie de cómics”. (Groth et al 87; traducción mía)
\end{abstract}

Junto a los cómics tradicionales y contraculturales, junto al cine tradicional del Hollywood de los cuarenta y cincuenta y al extranjero de Fellini, Buñuel y De Sica (Groth et al), la tercera fuente de la creatividad de Hernández es su propia tradición familiar y étnica:

Siempre hubo estas estupendas historias que habíamos escuchado de nuestros tíos y tías y nuestra abuela. Ellos contaban estas grandes historias de la época en que vivían en México o de cuando vivían en Texas, que es de donde es la familia de mi madre. Y

\footnotetext{
3 Ya adulto y consagrado -aunque con frecuencia necesitado de dinero-, Hernández ha trabajado también con las grandes empresas como DC Cómics y Dark Horse (Royal 233).

4 Para un excelente análisis formal del uso del lenguaje cinematográfico en Palomar, véase Hatfield, capítulo 3.

ISSN 0034-9631 (Impreso)
} 
pensábamos: “si tan sólo pudiésemos contar estas historias”. Pero se nos ocurría que nadie iba a lograr entenderlas. [...] pero al mismo tiempo había películas sobre niños blancos con elementos similares, y yo pensé si los blancos pueden entender eso podrán también entender esto. (Groth et al 88; traducción mía) ${ }^{5}$

Lo que rescata a la mayor parte de la serie de Palomar de esta mezcla heterodoxa de fuentes y de su potencial caída en un romanticismo melodramático o en un surrealismo mecánico o costumbrista, es la actitud iconoclasta y contracultural del punk y la cultura alternativa de los Estados Unidos que vivió Hernández, en los mismos años que vieron el ascenso de Ronald Reagan al poder. Esta actitud irreverente y vigilante quiere sorprender permanentemente y hacerlo de una manera que no siga otra moralidad o consideración que la que el relato y su propia lógica sugieren. La vigilancia permanente intenta evitar el cliché o el estereotipo, o hacerlos explotar con una energía inesperada:

[...] era la época en que Jaime y yo y algunos amigos habíamos estado participando de la escena rock punk en Los Angeles y eso abrió nuestros ojos para decir: "A la mierda con todo el mundo, yo sólo voy a hacer mi trabajo, a mi manera. No tengo nada que perder”. (Groth et al 89; traducción mía)

De este modo, el neorrealismo de lo social, el surrealismo que libera la imaginación y el humor, el realismo mágico que describe desde la cotidianidad una otredad de lo real tan vivida como deseada, el suspenso del thriller y del género negro (manifiestos en un gran momento de la serie como es Human Diastrophism) son todos mecanismos en una maquinaria de la representación para la cual el problema central es cómo comunicar una historia de latinoamericanos y latinos a una audiencia norteamericana dominantemente blanca y monolingüe en inglés, sin sucumbir al poderoso aparato representacional que esta cultura ha desarrollado para relacionarse con la otredad étnica o racial.

Hernández es muy explícito al respecto:

Mi meta es contar historias que sean atractivas y entretenidas para un público general, pero específicamente humanizar a los latinos, dar un ángulo diferente sobre los latinos, distinto al que es usado normalmente en la cultura popular [dominante] [...]. Creo que los chicos latinos no se ven a sí mismos en la cultura. Crecen como crecí yo, leyendo los cómics de la cultura dominante sobre personajes anglos -lo que está bien, hay algunos grandes cómics- pero no los veo pensando, “¿cómo podría ponerme a mí mismo en estos cómics” sin convertirme en un cliché? (Royal 223-24; traducción mía) ${ }^{6}$

5 Para una lista más completa de influencias artísticas en Gilbert Hernández, véase Rubin, 182.

6 Y también: "Yo trato de evitar muchos de los clichés, como el machismo en los hombres, la imaginería religiosa pesada que está en mucha de la cultura hispánica. No es que no esté allí, pero es fundamentalmente en lo que la gente asume cuando piensan en ella. Y yo he evitado eso, y lidio más en la vida de los personajes” (Bolhafner).

$\begin{array}{llllll}\text { Revista Iberoamericana, Vol. LXXVII, Núm. 234, Enero-Marzo 2011, } & \text { 177-193 } \\ \text { ISSN 0034-9631 (Impreso) } & \text { ISSN 2154-4794 (Electrónico) }\end{array}$ 
Si evitar las formas de la identificación alienante y los estereotipos que la cultura dominante ofrece a los sujetos subalternos para la representación y domesticación de su diferencia étnica y cultural, si ese es el desafío hacia la audiencia exterior, existe al menos otro desafío igualmente importante que mira hacia la audiencia interna o étnica:

Hice que mi Palomar reflejara una cultura latina más general. Se parece mucho a México, pero en verdad sólo quería que cualquier latino de cualquier parte sintiera que pertenecía a ese mundo. Era una suerte de universo paralelo en que cabía cualquiera [...]. Todo es mítico, y creo que los lectores latinos de todos los tipos podrían encontrarse allí. (Royal 227-28; traducción mía)

Esta doble direccionalidad que busca evitar las trampas de las formas de representación dominantes, a la vez que entiende la necesidad de atraer tanto al público externo mayoritario como al interno minoritario, esta "visión periférica" que obliga a mirar siempre desde el otro lado para comparar cómo se verían las cosas desde allí (Castañeda y Zavella 131), tiene tal vez su expresión más directa en las historias de Palomar que tienen que ver con Heraclio, Tonantzin y Miller.

Como Luba, Heracliollegó a Palomar, no nació en el pequeño pueblo de 386 habitantes (36). No es, pues, nativo y, sin embargo, Pintor, el niño que murió aplastado por el auto de su padre, deja que lo vea cual fantasma, cosa que el niño sólo hace con sus amigos de banda (33). Desde ese momento, Heraclio es parte del pueblo y, no obstante, desde su posición posterior de intelectual residente (a diferencia de todos sus amigos fue a la universidad, lee y conoce lenguas indígenas) y de alcohólico, puede ver con distancia cosas que muchos otros no logran ver. Al mismo tiempo, su perspectiva de mundo es radicalmente transformada tanto por la visión del fantasma como por los intentos sexuales de Luba hacia él, que culminarán en su paternidad, siendo aún adolescente, de una de las hijas de Luba. Estas son las dos formas de bautismo y aceptación de Heraclio en Palomar, de su entrada en la interioridad del pueblo, y ambas dejan su huella en el aspirante intelectual: "Heraclio intentó entonces empezar a lidiar con los problemas de la incertidumbre de los eventos recientes que obviamente cambiaron su visión de la vida (y de la muerte) en Palomar (y en nuestro mundo)” (G. Hernández 33; traducción mía).

Antes de seguir con Heraclio, valdría aquí la pena hacer un breve aparte sobre el aparte mismo en Palomar. En efecto, la interrupción de la narración con un comentario metatextual y también la interpelación directa al lector son dos procedimientos frecuentes en el arsenal de Hernández, destinados igualmente a desfamiliarizar la percepción de su audiencia, a hacerla pensar en las formas de tropicalización y contra-tropicalización potencialmente involucradas. En una de las primeras páginas de Palomar, una figura que duplica a la del autor nos mira directamente a través de la página para decirnos: "pero por supuesto, nosotros sabemos la historia verdadera, ¿no?” (16). Más tarde, otro personaje nos mira de nuevo directamente y señala: "Supongo que, después de todo, ella [Luba]

\footnotetext{
\begin{tabular}{l} 
Revista Iberoamericana, Vol. LXXVII, Núm. 234, Enero-Marzo 2011, $177-193$ \\
\hline ISSN 0034-9631 (Impreso)
\end{tabular}
} 
prueba que la verdad es más fascinante que la ficción” (80). Y en directa referencia a su propio proceso de serialización, al final de uno de los capítulos, se apunta: "Y bien! Parece que otra entrega de Heartbreak Soup ha llegado a su fin, así es que ¿qué tal si la terminamos en un final feliz por una vez? Hasta la próxima...” (103).

En otro momento mucho más desarrollado, que combina muy bien los imaginarios realistas y fantásticos que están en la base del verosímil que anima Palomar, una Tonantzin vestida como si fuera un cruce entre Carmen Miranda y una super-heroína se dirige de frente a los lectores para decirles: "Sí, [Carmen y Heraclio que han tenido un conflicto matrimonial] estarán allí [en su casa] todo el día haciendo las paces. ¿Qué quieres decir con 'eso es todo’? ¿Qué quieres, sangre todo el tiempo?” (239). De este modo, Hernández juega con los lectores, cómplices o no, a la vez que los hace conscientes de sus expectativas genéricas (sangre y sexo) y socio-culturales. Esto es aquí parte de una sofisticada estrategia semiótica de tropicalización y contra-tropicalización orientada a destacar la existencia y tensión en el texto de al menos dos imaginarios culturales y de múltiples tradiciones discursivas.

La advertencia más fuerte la proporciona un borracho que, sentado en la calle, nos espeta a los lectores mirándonos a la cara: "No son más que un montón de sucios y apestosos voyeristas. ¡Eso es lo que son! Si, ustedes” (87); mientras en otro momento de guiño cómplice, un joven a quien una chica muy guapa le acaba de decir “ ¡Hola forastero! Por qué no me sacas de aquí” nos mira de frente y nos pregunta con una sonrisa socarrona: “¿les ha pasado alguna vez tener un día así de bueno? (153, pregunta repetida también a propósito del sexo inesperado en 209).

Heraclio perdió su virginidad a los 15 años a manos de una suerte de súper mujer (Luba) que todos los hombres deseaban pero no podían alcanzar, pero está casado con una mujer que lo ama y es bajita e ignorante en letras, aunque sabia en su sentido común. También en este sentido, Heraclio es un álter ego del autor, cuya imaginación visual y sexual fue desarrollada desde muy temprano por las heroínas de los cómics tradicionales para terminar combinándolas con estas mujeres de carne y hueso que habitan Palomar y habitaron su entorno familiar y barrial en Oxnard, California. Esta coexistencia de varias formas de representación de las mujeres importa también para destacar otro momento de alta conciencia respecto a la heterogeneidad de imaginarios y discursos que animan Palomar.

En Love Bites (parte del libro Palomar) vemos la tensión entre Heraclio, que es profesor en una escuela cercana, y su esposa, Carmen, quien no puede tolerar que su marido prefiera a veces la compañía de sus libros a su conversación: “¡Heraclio esta es la última vez que me vas a ignorar por esta porquería! [dice Carmen, a lo que Heraclio responde:] ¡Porquería! ¡Es Cien años de soledad de Gabriel García Márquez! Es estupendo" (229; traducción mía). Cuando Carmen le pide finalmente que le cuente de qué trata el libro, Heraclio responde "Es sobre nosotros. Es sobre nuestras vidas. Bueno no nuestras vidas, pero [...]” (230).

\footnotetext{
Revista Iberoamericana, Vol. LXXVII, Núm. 234, Enero-Marzo 2011, 177-193
ISSN 2154-4794 (Electrónico)
} 
El corte nos muestra un poco más tarde a Heraclio en conversación con una atractiva colega profesora que le interroga juguetonamente sobre literatura que ella llama “clásica”, desde Don Quijote a Crimen y castigo, pasando por Moby Dick. Cuando Heraclio le pregunta quién es Prudencio Aguilar, Gloria reconoce su ignorancia y Heraclio exclama: “ ¡Es el fantasma que es indirectamente responsable de la fundación del pueblo Macondo en Cien años de soledad de Gabriel García Márquez!” (231), a lo que Gloria responde que Cien años es tal vez una obra maestra pero no exactamente un "clásico". Cuando Heraclio insiste en el doble carácter de obra maestra y clásico del libro de García Márquez, Gloria añade: "seguro, si te gusta la repetición interminable y la hipérbole infantil, aunque debo reconocer que algunas partes son bastante buenas”, a lo que Heraclio responde, finalmente, con una descripción que bien podría aplicarse a Palomar: “¿Buenas? El libro es divertido y triste, cálido e informe, progresista y loco, y simplemente brillante” (232).

Que luego el texto pase a la tristeza infinita de Carmen por la pelea con su marido y por su impotencia ante esos libros que apenas sabe leer, y a la borrachera de Heraclio que lo lleva directo a los brazos de Luba que lo escucha pacientemente quejarse, para terminar, en un pasaje ya citado, con la figura hipersexualizada y tropical de Tonantzin en su atuendo a la Carmen Miranda interrogando directamente al lector sobre sus expectativas de lectura; que todo eso ocurra en una misma entrega es una muestra clara de la intensidad metatextual que Palomar alcanza a veces en su esfuerzo por relacionarse con al menos tres audiencias diversas que emplearán protocolos de lectura diferentes. Esas audiencias incluyen aquí la dominante blanca y monocultural, para quien Cien años de soledad ( y por extensión Palomar mismo) puede ser reducido con frecuencia a un par de tropos negativos; la audiencia tradicional de los cómics más interesada en la visualidad hiperdesarrollada de la representación gráfica convencional del sexo femenino y la violencia masculina y, finalmente, la étnica latina y latinoamericana de la cual se espera mayor simpatía.

Creer, sin embargo, que la filiación con García Márquezy la literatura latinoamericana canónica "explican" completamente la filiación narrativa de Palomar sería un error reductivo comparable al de Gloria, más arriba. A ello tal vez alude uno de los complicados guiños discursivos con que empieza toda la saga. Como se recordará, Manuel, el latin lover, siempre sonriente y mujeriego, y Soledad, que es simultáneamente el trabajador latinoamericano inmigrante en los Estados Unidos y un intelectual cuyo nombre es Soledad y cuyo apellido es Márquez, se autoeliminan en las primeras entregas de Palomar. Manuel se acuesta con Pipo en la casa vacante que Soledad ha dejado, y este último que ha retornado temporalmente en un aparente rapto de celos (él y Manuel habían tenido relaciones sexuales) mata a Manuel (54). Al hacerlo, ambos desaparecen de Palomar, aunque los flashbacks le permitirán a Hernández rescatarlos en algunas ocasiones. Ambos dejarán en el lector -y por cierto en el autor, quien se muestra igualmente sorprendido por la muerte de Manuel con quien simpatizaba (Groth et al)- la impresión de una

\footnotetext{
\begin{tabular}{l} 
Revista Iberoamericana, Vol. LXXVII, Núm. 234, Enero-Marzo 2011, $177-193$ \\
\hline ISSN 0034-9631 (Impreso)
\end{tabular}
} 
posibilidad sin cabal desarrollo. Habrá luego otros amantes latinos pero estos serán, como se insinua de Manuel, decididamente bisexuales, como en el caso de Israel, o terminarán viendo reducida su belleza física a una grotesca desfiguración, como en el caso de Khamo. Las cosas en Palomar, parece decir Hernández muy tempranamente y para su propia sorpresa, no calzarán nunca con la comodidad que la estructura de expectativas de un solo grupo de lectores, operando desde los presupuestos culturales y narrativos de un solo imaginario, reclama. Habrá en cambio, con frecuencia, un fuerte trabajo de hipercodificación, descodificación y resemantización de los códigos narrativos y culturales de los géneros específicamente involucrados (desde la novela, a los diversos tipos de cómics, pasando por los filmes hollywoodenses y extranjeros). Esa es la estrategia semiótica de tropicalización y contra-tropicalización de Palomar, a la que me he referido aquí con insistencia.

Aunque previsible, tal vez no sea del todo inadecuado concluir este ensayo discutiendo dos figuras intradiegéticas o álter egos de Gilbert Hernández en Palomar, que representan algunos de los escollos que su empresa le ha significado y que Disney no pudo superar en los años cuarenta.

En algún momento, Heraclio recordará la historia de Howard Miller, el fotógrafo estadounidense que llegó a Palomar para "usar al pueblo como el tema de un diario/ reportaje fotográfico”. Miller le cuenta a Heraclio que él estuvo en Camboya, Nicaragua y Sudáfrica y también El Salvador, donde se ocupó de la violencia en la guerra civil. De acuerdo a Heraclio, Miller "quería esta vez mostrar la pura belleza de la inocencia en vez del horror que normalmente la destruye” (254).

Las buenas intenciones de Miller importan por lo que dicen de su visión romántica de Palomar, pero también porque él terminará involucrándose con la joven Tonantzin -a quien le insinuará la posibilidad de un futuro profesional en modelaje-y abandonando a la carrera el pueblo cuando ella quede embarazada. Desde su llegada a Palomar, Miller ha estado buscando capturar “la condición humana con su cámara” (193) pero terminará, en cambio, descubriendo la suya cuando se involucre con Tonantzin. Cuando Miller ve a Luba trabajando en frente de su cine popular, le propone hacer al día siguiente una serie de fotos con su familia y piensa para sí mismo: "Fantástico. Ojalá que el resto de su familia se vea tan destartalada [como ella]” (195). Cuando al día siguiente Luba, perfectamente arreglada, le propone tomar las fotos en frente de su casa porque el "cine es demasiado feo, usted entiende”, Miller es quien le dice que ella no entiende, que lo él quiere es otra cosa:

[Luba] ¿Usted quiere una foto de mi familia toda desordenada y mugrienta para [...] ponerla en un libro que todo el mundo verá? ¿Qué se cree que somos, un show de curiosidades [a freak show]?

[Miller]: No, no, usted no entiende. Quiero mostrar la belleza de sus vidas pueblerinas [...]

Revista Iberoamericana, Vol. LXXVII, Núm. 234, Enero-Marzo 2011, $177-193$
ISSN 2154-4794 (Electrónico) 
[Luba] ¿Belleza? Usted se va a ganar cientos de dólares mostrándonos de la peor forma y usted me habla de belleza? (197)

Lo que presenciamos, y que terminará cuando Luba las emprenda a golpes contra Miller y éste se quede pensando “¡Que mierdas sabe ella de arte!”, es una suerte de metaencuentro semiótico en donde las amplias posibilidades para la tropicalización dominante del otro étnico son exploradas a cabalidad.

Tonantzin -quien siempre quiso abandonar el pueblo para irse a Hollywood o casarse con alguien rico que la sacara de allí- parece estar usando a Miller tanto como él a ella. Una viñeta sin imágenes en la que sólo vemos los pensamientos de cada uno nos lo aclara:

[Miller] Pobre chica. No se da cuenta que no tiene ninguna posibilidad de hacer nada en el mundo del espectáculo. Por otro lado lo que no sabe no puede hacerle daño. Terminará olvidándose de mí y de Hollywood tan pronto me vaya.

[Tonantzin] Supongo que no estará tan mal vivir con él en los Estados Unidos. Espero que la comida y la música no sean tan malas como dicen que son. (194)

Esta suerte de escena original del colonialismo no escapará a la suerte de sus antecedentes históricos. ${ }^{7}$ Tonantzin acabará de descubrir luego, aunque de manera muy confusa, la política y abandonará Palomar con Khamo, su amante, con la intención de ayudar a otros a derrocar gobiernos injustos para terminar prendiéndose fuego en frente de una embajada. Miller, ya de vuelta en los Estados Unidos, verá la escena en televisión con su novia norteamericana y cuando ella le pregunte cómo es posible que alguien esté tan loco como para autoinflingirse tanto dolor, él responderá:

No, para nada. Esas personas no están locas ni son autodestructivas. Son gentes profundamente heridas por un mundo que se ha ido a la mierda alrededor suyo [...] En el caso concreto de esa chica [Tonantzin en la imagen de la televisión] no te sabría decir $[\ldots](423)$

El otro álter ego del artista en Palomar es Humberto, ${ }^{8}$ y él representa un peligro de otro tipo. Si la falla moral de Miller revela a alguien más preocupado de su propia carrera en ascenso que de las violencias políticas y sociales sobre las que trabaja con cierto efectismo profesional, Humberto cree en su vocación con un fervor tan exclusivo

7 Una figura relacionada pero más familiar es la de los dos jóvenes turistas que han venido a surfear al pueblo. (333)

8 William Nericcio ha llamado a la historia de "Humberto una suerte de cuasi-memoria autobiográfica de un joven artista, un inspirado e inocente aspirante a artista. [... ] Wilhelm Meister de Goethe re-imaginado como un artista al sur de la frontera” (Nericcio 99; traducción mía).

(IS) $\frac{\text { Revista Iberoamericana, Vol. LXXVII, Núm. 234, Enero-Marzo 2011, } 177-193}{\text { ISSN 2154-4794 (Electrónico) }}$ 
que no deja espacio a ningún otro tipo de consideración. Humberto es, en efecto, un chico de gran talento natural para el arte, a quien Heraclio le presta sus libros para que descubra aun sin saber leer bien, con la ayuda de Posada, Miró, Kandinski y Modigliani, lo que terminará siendo una relación cuasimística y completamente absorbente con el arte mismo y con su capacidad para representar a las personas y sus historias en Palomar (336). Por ello, por su misma fidelidad al arte así concebido, cuando se produzca una serie de asesinatos en el pueblo, Humberto quien ha descubierto al criminal in fraganti, no lo denunciará ante la ley sino que intentará representar artísticamente la escena. Recriminado por la sheriff Chelo -"Cinco personas muertas desde el día en que dices haber visto lo que viste. ¡Cinco, Humberto! Estarían vivas hoy si nos hubieses dicho inmediatamente" (390)-, Humberto se limita a señalar con una mirada enajenada: "El Arte, el gran Arte revela las verdades más profundas” (390). Cuando Chelo le prohíbe dibujar o pintar, Humberto se dedica secretamente a esculpir grandes estatuas que representan a los habitantes de Palomar en piedra, que luego instala en el fondo del río. Cuando Petra lo descubre, él señala: "Sé que usted ha escuchado que no se me permite pintar o dibujar, pero yo debo crear [...] o morir. Algún día esta corriente desaparecerá y las estatuas quedarán a la vista, alzándose hacia dios, el sol, como flores eternas, y se me perdonarán mis pecados” (517).

Esta defensa emocionada y mística, pero también parcial y limitada, de los poderes y responsabilidades del arte, ocurre en el contexto físico de las grandes estatuas de piedra que los antiguos habitantes indígenas de Palomar levantaron hace siglos. Ello nos habla del esfuerzo de filiación y de raigambre que anima al arte a veces provocador y siempre autoconsciente de Gilbert Hernández en Palomar. No sorprende entonces que en el comienzo mismo de la historia del pueblo se hallen la figura de Heraclio -quien devendrá el intelectual cuyas peripecias, a lo largo de la historia del pueblo, son aquí lo más cercano a un héroe masculino en toda la serie- y Pintor, el niño muerto pero de espíritu presente que bajo el árbol del bien y del mal, en donde ocurrirán tantas cosas en Palomar, se muestra sólo a quienes saben ver. Que el nombre del niño fantasma sea Pintor nos recuerda que para poder ver lo que hay que ver en Palomar, para entender el arte del pintor-autor que es Gilbert Hernández, es necesario leer entre lenguajes, entre el imaginario latin/o/americano y el norteamericano, con el fin de realizar desde allí las varias formas de traducción lingüística, conceptual y cultural que sus constantes esfuerzos de des/tropicalización y contra/tropicalización exigen.

\footnotetext{
Revista Iberoamericana, Vol. LXXVII, Núm. 234, Enero-Marzo 2011,
ISSN 0034-9631 (Impreso) 
Aparicio, Frances R. “On Subversive Signifiers: Tropicalizing Language in the United States”. Tropicalizations. Transcultural Representations of Latinidad. Frances R. Aparicio y Susana Chávez-Silverman, eds. Hanover: Dartmouth College, 1997. 194-212.

y Susana Chávez Silverman, eds. Tropicalizations. Transcultural Representations of Latinidad. Hanover: Dartmouth College, 1997.

Benfer, Amy. “Real Women”. Salon.com. 20 feb. 2001. < http://archive.salon.com/mwt/ feature/2001/02/20/Hernández/print.html>. 3 enero 2011.

Bolhafner, Stephen. “No Joke: Comics for grownups”. St. Louis Post-Dispatch (3 enero 1993): 4-C.

Burton, Julianne. “'Surprise package’: Looking Southward with Disney”. Disney Discourse. Producing the Magic Kingdom. Eric Smoodin, ed. New York: Routledge, 1994. 131-47.

Castañeda, Xóchitl y Patricia Zavella. “Changing Constructions of Sexuality and Risk: Migrant Mexican Women Farmworkers in California”. Journal of Latin American Anthropology 8/2 (2003): 126-51.

Dávila, Arlene. Latinos Inc. The Marketing and Making of a People. Berkeley: U of California P, 2001.

Groth, Gary, Robert Fiore y Tom Powers. “The Hernández Bros. Interview”. The Comics Journal 126 (enero 1989) 61-113.

Fernández-L'Hoeste, Héctor y Juan Poblete, eds. Redrawing the Nation: National Identity in Latin/o American Comics. New York: Palgrave, 2009.

Hatfield, Charles. Alternative Comics: An Emerging Literature. Jackson: UP of Mississippi, 2005.

Hernández, Gilbert. Palomar. The Heartbreak Soup Stories. Seattle: Fantagraphics Books, 2003.

Hernández, Jaime. Locas. Seattle: Fantagraphics Books, 2004.

Merino, Ana. "Los Hermanos Hernández: El pulso latino en la vertiente alternativa del cómic estadounidense”. Redrawing the Nation: National Identity in Latin/o American Comics. Héctor Fernández-L’Hoeste y Juan Poblete, eds. New York: Palgrave, 2009. 251-70.

Nericcio, William Anhony. “Artif[r]acture: Virulent Pictures, Graphic Narrative and the Ideology of the Visual”. Mosaic 28/4 (1995): 79-109.

Piedra, José. “Pato Donald’s Gender Ducking”. Disney Discourse. Producing the Magic Kingdom. Eric Smoodin, ed. New York-London: Routledge, 1994. 148-68.

Pike, Frederick B. The United States and Latin America: Myths and Stereotypes of Civilization and Nature. Austin: U of Texas P, 1992.

Revista Iberoamericana, Vol. LXXVII, Núm. 234, Enero-Marzo 2011, $177-193$
ISSN 2154-4794 (Electrónico) 
Poblete, Juan. "Literatura, heterogeneidad y migrancia trasnacional”. Nueva Sociedad 201 (2006): 90-105.

Royal, Drek Parker. "Palomar and Beyond: An Interview with Gilbert Hernandez". MELUS 32/3 (2007): 221-46.

Rubin, Rachel. "Love and Rockets”. Aztlán 24/2 (1999): 169-88.

Smoodin, Eric. Disney Discourse. Producing the Magic Kingdom. New York-London: Routledge, 1994.

ISSN 0034-9631 (Impreso) 
